Economic and Industrial Democracy

EID-13-0512

Original Article

Country: United Kingdom

\title{
When Do Health and Well-being Interventions Work? Managerial Commitment and Context
}

Abstract

\section{Kay Greasley and Paul Edwards}

Health and well-being interventions are increasingly assessed as complex processes rather than randomized controlled trials. In this study the health and wellbeing interventions refer to voluntary actions and are not in response to any regulatory requirement. This paper looks specifically at managerial commitment to these interventions and at the organisational context in which they occur. Ex-ante study predictions as to the effects of commitment in three organisations were made and then followed up. This commitment was positively associated with employee perceptions of health promotion campaigns. But broader impacts, such as commitment to the organisation and a sense of autonomy, were not evident. The explanation lies in wider features of the organisation of work: permanent constraints such as job design and shift systems ran against the aims of the health interventions. Relating well-intentioned interventions to such features of organisational life remains a challenge for many organisations.

Key words: Employee health, Human resource management, Intervention studies, Well-being 


\section{Health and well-being, interventions, realist evaluation}

Interventions to address issues of workplace health and well-being have a long history. As Cox et al. (2007) demonstrate, the dominant approach has been that of the randomized controlled trial. They argue for a 'more broadly conceived and eclectic' approach that will address the nature of interventions in the 'real world' (p. 358). Features of the real world include the fact that organisations do not sit passively waiting to be case studies but, rather, shape interventions to suit their own purposes. The conditions for true experimental conditions are rarely present in practice. Frameworks recognizing the 'embeddedness' of interventions in 'complex social structures' but also noting the 'scarcity' of empirical studies are beginning to emerge (Nielsen and Abildgaard, 2013). The present paper offers an empirical study that contributes to this emerging agenda; though conceived before the formalization of the frameworks, and thus not applying them directly, it is consistent with them.

It makes two arguments in particular. First, the nature of managerial commitment to an intervention shapes its character: it is not the intervention itself that is key, but the meaning given to it by participants. As Cox et al. (2007: 355) remark, the management of an implementation is an important key to its success (see also Sisson and Storey, 2000). Secondly, the degree of success of an intervention is shaped by wider organisational conditions. Variation in 'macro processes in the wider organisational, social and socio-economic, and political contexts may explain why some interventions are successful while others are not' (Cox et al., 2007: 35). Yet little 'is known about the ways in which nominally similar work practices are shaped by particular organisational conditions' (Vallas, 2003: 224). This latter theme is central. Experimental studies necessarily control for the environment. They may find effects when other influences are absent, but in the reality of organisations managers need to know whether the effects will continue to exist when wider influences are taken into account. The reality of concurrent changes faced by organisations should therefore be considered the norm and be integrated into intervention designs (Nielsen et al, 2010a).

The kinds of organisations likely in practice to deploy interventions, moreover, are not a random selection of all organisations. As Ichniowski and Shaw (2009) point out, workplace innovations are adopted by certain types of organisations, and what is interesting is what happens in them, as opposed to average effects across all organisations. In the present study, we were not able to assess large-scale socio- economic or political factors, though the extent to which they prevent managers from keeping their promises is an important overall factor conditioning success (Thompson, 2003). We consider variations between organisations within the same economic context.

A particular contribution is that we provide a real-time assessment. Many studies of change programmes look backwards from an outcome to infer the effects (Wilkinson et al., 1992; Marchington et al., 1994; Rosenthal et al., 1997). We were able to assess the degree of managerial commitment and make predictions ahead of the outcomes (Greasley et al, 2012). 


\section{Assessing Interventions in Health and Well-being}

Organisational interventions

Interventions are 'planned actions that are designed to remove or modify the causes of job stress and impaired health and well-being, and that target relatively large groups of people in a relatively uniform way' (Nielsen et al., 2010a: 220). The attribute of being 'theory-based' has also been identified (Nielsen and Abildgaard, 2013: 278). The interventions studied here fit these definitions in that they were planned by the organisations concerned, aimed to affect health and well-being of all of a defined group of workers, and were theory-based in deriving from the analysis of a specialist consultancy in the field.

Concerns about experimental efforts to measure effects are part of a wider disquiet among social scientists about the treatment of randomized control trials as the gold standard. As Pawson et al. (2005) argue, the model of causality in such trials is a 'successionist' one whereby Cause X is switched on and Effect $\mathrm{Y}$ follows. In contrast, they argue for 'generative' model that addresses both the mechanism that links $\mathrm{X}$ and $\mathrm{Y}$ and the variability in context; the latter means that $\mathrm{X}$ may precede $\mathrm{Y}$ under some conditions but not others. The relevant question is: 'what is it about this programme that works for whom in what circumstances?' (Pawson et al., 2005: 522).

These arguments can be located in relation to a study using randomization (DeJoy et al., 2010). This has three relevant features. First, it looked at a broadly-based set of interventions, as opposed to the very concrete ones that are the focus of most experimental studies; our study had a similar focus. Secondly, it distinguished between proximate, intermediate, and distal effects of interventions in ways similar to ours. Third, it was able to take account of external conditions: it found that in its experimental group many measures of outcomes worsened over time as a result of other factors, but this worsening was even steeper in the control group. The present study complements that of DeJoy et al. by taking a more sociological approach to what interventions mean, and by looking at different real-world cases. As Macfarlane et al. (2011: 61) note in a study of a wide-ranging change management programme, the 'same' intervention can in fact be put into effect in very different ways in different organisations. Similarly we recognise the importance of formative evaluation (in terms of exploring the intervention process) alongside the more traditional summative evaluation approaches (the survey outcomes). Nielsen et al (2010a) describe the inclusion of both approaches as a mechanism to enable understanding the how and why of successful interventions (or absence of). In this paper, the formative evaluation allows an interpretation of the outcomes of the health and wellbeing interventions. 
The formalization of such ideas by Nielsen and Abildgaard (2013) identifies four stages of the intervention process: the actors driving it, the mental models that they use to makes sense of it, the context, and the intervention design and process. We comment on all of these, though focus on the context in particular.

\section{Health and well-being}

In the UK a significant proportion of employers are increasingly taking an interest in the health of their workforce and introducing a range of health and wellbeing interventions (CIPD, 2009). These interventions presented in this study are entirely voluntary, and additional to legal requirements in relation to health and safety. The present study did not consider the linkages between law and practice (on which see Tombs and Whyte, 2012). The aim here is not to explore innovations organisations were obliged to undertake to support health and wellbeing; rather it is to examine wellbeing innovations that go beyond the statutory requirements.

Although the impact of a healthy workforce on organisational performance can be debated, there are several studies which clearly identify the link between ill-health and outcomes such absence (Marmot et al., 1995; Smulders and Nijhuis, 1999). It could be reasonably argued that to be 'well' serves the interest of the employers and the employees. Certainly there is evidence that where employees report good health this is reflected in improved mortality rates (Idler and Benyamini, 1997). The UK government emphasizes the need to promote a well workforce; the work of Dame Carol Black (2008) in “working for a healthier tomorrow” and MacLeod and Clarke’s (2009) report on 'engaging for success' are but two examples. In the latter the authors point to 'positive enablers' and potential barriers for organisational engagement. Specifically they argue that failures can be related to: lack of senior management support, need for practical support and advice, poor line management and cynicism of employees. It is evident that there is an emphasis, at least in theory, for organisations to offer wide range of health and wellbeing support for employees that goes beyond statutory requirements. It is this additional support activities for health and wellbeing that is the focus of this study.

Although it could be argued that any initiative has the potential to face employee resistance, in this case the intervention is relatively benign when compared against TQM and flexible production for example. In the latter examples the critics are clear that the quality initiatives are instigated to control and structure meaning for employees; indeed Harrison (1994) underlined the 'dark side' of this form of production. Yet some such interventions can bring gains to workers relative to other options (Edwards, 2005). We would therefore anticipate that initiatives aimed at supporting employees' health and well-being, may not be wholly embraced, would face fewer challenges than those that may increase workloads and responsibilities as maybe found with TQM initiatives. 
This is not to say that health and well-being innovations are an uncontested area. We recognize the numerous sceptical accounts of the value of HRM (Legge, 2005). As Hyman (2006: 199) shows, there are circumstances in which workers feel empowered, but the extent of 'genuine opportunities for employees to gain substantive or strategic control over work' remains tightly constrained. In relation to health, Baldry et al. (2006: 252) conclude from their research on call centres that, 'when a task which is itself stressful' is performed in an 'unsupportive' work environment that requires extensive interaction with technology above recommended levels, 'a reduction in employee health and well-being must inevitably occur'.

The nature of wellbeing interventions predominately focuses on the individual and the pursuit of changes in their behaviour and attitudes. Commonly organisations do not adapt work practices to reduce the organisational sources of stress (Murphy, 1988 cited in Nytrø et al 2000). In so doing issues of power, work organisation and autonomy are avoided, issues which impact occupational illness (Bohle and Quinlan, 2000 cited in Nytrø et al, 2000). These conclusions are reflected in the work of Taylor et al (2003). In their work on call centres they found that managers were much more likely to address proximate issues (for example, ergonomic issues) rather than those that relate to work organisation. The increased competitive pressures remain a constant resulting in a continuation of occupational ill-health (Taylor et al, 2003).We share much of this overall sceptical view of HRM in practice. Our results point to the limited impact of health interventions on issues such as commitment and autonomy. But what is their impact on more proximate matters such as employees' perceptions of their own health?

The post-experimental literature on interventions identifies several factors that shape success including the motivations of those designing the implementation, possible differences between senior and line managers (Cox et al., 2007), the extent to which adequate training is provided (Nielsen et al., 2010b), how employees respond to and interpret the intervention (Randall et al., 2007), and the organisational context (Cox et al., 2007; Nielsen et al., 2010b). The present study was designed to address two of these, the implementation process and the wider context.

In relation to the former, Bach (2005: 38) remarks in broad terms on the importance of the 'will and ability of senior managers' to institute change. Specific studies illustrate the point. Shaw et al. (2003) found that key personnel (in this case line managers) can act as barriers or enablers. Rainbird et al. (2003: 44) speak of a need for 'enthusiastic local actors' to press initiatives through. Wright and Edwards (1998) identify the important role played by an individual HR manager in pressing through a change initiative. Baril et al. (2003) make a similar point specifically in relation to health interventions. In the work of Nytrø et al (2000) the process issues associated with the implementation of occupational stress interventions were explored. They argue that it is insufficient to simply examine the intervention per se, it is necessary to consider both the process and context in which the intervention occurs. Health and wellbeing interventions do not occur in a vacuum; rather they occur against a backdrop of downsizing, cynicism and failure. This may result in employees' lack of enthusiasm or indeed sabotaging the latest innovation (Nytrø et al, 2000). In our paper we consider how well-being interventions were defined and implemented in contrasting 
organisations.

In relation to context, managers often feel that they are unable to implement health management policies. They may be reluctant to amend targets and breaks due to perceived constraints of competitive pressures (Taylor et al., 2003). Baril et al. (2003) found that, while modified work (amending the work task or work practice to accommodate the health demands of employees) could be accommodated initially, an increase in production demands would result in an abandonment of such modifications so that production targets could be met. D'Cruz and Noronha (2011) in their work of high commitment management in Indian call centres reiterate this view. Promoting employee wellbeing requires consideration of a holistic approach, including the task demands placed upon the employee. The primary focus for competitive advantage results in employee wellbeing consistently relegated to a 'secondary position' (D'Cruz and Noronha, 2011: 199). The impact of increased working pressures and the relegation of employee wellbeing are not without consequences. Reports from the World Health Organisation (2007) have identified associations between increased work pressures, downsizing and precarious work with poorer health outcomes. For example, the use of precarious employment (used as a tool to meet competitive demands) may result in employees having less control over their work process, high levels of stress and producing adverse health outcomes. There would appear therefore a disconnect between the espoused interest in promoting health and wellbeing and the growing demands placed upon employees to meet these competitive pressures.

Wilkinson et al. (1992) found, in the case of quality initiatives, that implementation problems reflected wider uncertainties about the initiatives and political tensions between levels of management. Other features that have also been linked to the failure of initiatives are the prevalence of concurrent negative changes (Bambra et al., 2009). Marchington et al. (1994) take these points further. They show that the meaning of an initiative has to be related to history and context. An apparently modest scheme can be effective if introduced in an environment with no experience of involvement; but more developed schemes in contexts where involvement was established tended to fail because they did not meet employee expectations. As the contextual issues associated when trying to implement this type of intervention are not widely reported in the literature, this study will offer a crucial additional dimension to aid our understanding. For example, there is a call for consideration of the workplace context in which return to work interventions take place (Pransky et al., 2005). The adoption of a realist approach here enables an insight into not just the intervention outcomes but the contextual issues that have significant influence (Dieleman et al, 2009).

Following DeJoy et al. (2010), we expect the context to be most permissive in relation to the immediate effects of an intervention. Specific aspects of employees' practice around healthy behaviour are often targeted in interventions, and effects can reasonably be expected. As one moves to intermediate potential effects, as in such areas as job satisfaction, effects might be present but weaker. Finally, wider aspects of jobs such as autonomy and commitment may be more dependent on the underlying work organisation, and thus hardest to affect. 
We thus have two broad ideas to test. First, the degree of managerial ex ante commitment to an implementation programme will affect the degree of subsequent success. Second, this success will be moderated by organisational conditions such that the more distant aspects of work organisation will be the least affected. We can also take some account of the relationship between these factors: does the context wash out any effects of a high level of ex ante commitment?

\section{The Study}

In order to understand the nature of the interventions under study, we need to explain the process through which they took place. Such a history is often neglected, but to grasp why an intervention exists at all its origins require consideration.

\section{Organisation Selection}

The project team approached 86 organisations with which they had professional contact. Fifty-four of these expressed initial interest but subsequently withdrew because of internal pressures, or restructuring that might impact on the implementation of the wider project, or failed to respond to subsequent communication. The ultimate aim was to achieve a sample of 9 varied case study organisations in terms of sector, industry and nature of workforce. Following detailed explanation about the study, 14 organisations committed to participate in the study. Information about each organisation was gathered in a structured telephone interview with the nominated lead. Nine of these proceeded to the full study. They were two National Health Service (NHS) organisations, one police force, one local authority, two call centres, one manufacturing organisation, one power provider and one firm in heavy industry. The original 86 organisations were already among the most likely to be interested in interventions, in that they were known to and willing to engage with academic researchers; the reduction of this number to 9 points to the highly self-selected nature of organisations engaging in interventions, and warns against ideas of average effects (Ichniowski and Shaw, 2009).

This article utilizes 3 of the 9 case study organisations; details of those organisations are shown in Table 1. Rather than presenting all of the case studies in this article we utilize a carefully selected sample by way of illustration. The three case studies were selected here as they provide specific examples of three points on a continuum of engagement: the enthusiastic and fully engaged (one of the call centres, owned by a vehicle recovery service), the sporadically engaged (car manufacturer) and the nominally engaged (police force).The derivation of this continuum is explained in the ex-ante study (Greasley et al, 2012). This selection criterion provides an opportunity for comparing organisations with varying 
levels of managerial commitment.

The fully engaged organisation, the call centre, provides an opportunity to examine the outcomes of a health and well-being initiative in a potentially 'ideal world' scenario. As such we intend to focus on this organisation in order to understand what outcomes can be achieved in this fertile ground, using the police force and car manufacturer as comparator organisations. If our predictions are correct we would expect positive outcomes in comparison with the other two organisations.

\section{The Interventions}

We deemed the call centre to be fully engaged for two reasons (Greasley et al, 2012). First, the interest in the intervention reflected a concern to improve well-being, albeit with a view to efficiency. As one manager put it,

if you create a great working environment, people will feel happier and ultimately, yeah, okay, they will be more productive but they're going to stay with you longer hopefully, they're going to recommend you to friends.

In the other two organisations, by contrast, the main focus was on cost reduction and efficiency improvement. Secondly, in the call centre there was active enthusiasm during the design and initiation of the study. At the car manufacturer, such commitment was sporadic. At the police service, there was even more of a lip-service approach, with very little active engagement. All three organisations' activities none the less qualified as interventions as defined above: they facilitated tailored programmes with explicit well- being objectives.

A pre-intervention evaluation of the current state of affairs was made with each organisation. During this phase, a steering group was formed in each case study organisation, comprising a variety of organisational members. Once this group was established, baseline data were collected. A feature of the overall project is that organisations are offered an intervention by a consultancy firm, with a tailored programme being provided along with a set number of days for free advice. The consultancy process was separate from the research study and was observed as part of the research process. The organisations selected the interventions that they wished to implement from a 'menu' of options or could tailor an intervention for their needs. These were designed to enable organisations to work on areas that they wished to change, improve, or implement fresh, which could continue to run after the study was completed. Table 2 outlines the interventions and organisational change that occurred during the research period.

Methods 
The study utilised three methods:

1. Pre-intervention evaluation; this included qualitative interviews with a variety of stakeholders, observation and a questionnaire survey; its provided a baseline assessment of the organisation. As detailed below, methods embraced those recommended by Nielsen and Abildgaard (2013: 291), including 'keeping minutes of meetings relevant to the intervention, conducting interviews with employees managers and stakeholders, [and] recording field study notes from workshops and other key events'.

2. Intervention implementation: five days of consultancy/training (intervention implementation) with each participating organisation by an external human resource and health promotion consultancy firm during which organisations were assisted in developing and implementing a series of tailored interventions. This stage occurred after the pre-intervention evaluation.

3. Post-intervention evaluation including qualitative interviews with a variety of stakeholders, observation and a questionnaire survey. This phase enabled an assessment of any impacts of the intervention(s) approximately 12 months later.

The use of a mixed methods approach combining both quantitative and qualitative methods supports both a formative and summative evaluation of the intervention (Nielsen et al, 2010a and Dieleman et al, 2009). The experimental approaches traditionally applied for intervention evaluation, that is quantitative and outcomes focused, are complemented with observation and qualitative interviews through which the processes and context of the interventions can also be examined.

Qualitative interviews were intended to provide detailed insights into the experiences and perceptions of the various stakeholders within each case study organisation. At each organisation, it was important to conduct in-depth qualitative interviews with a variety of stakeholders to gain a range of perspectives. This included employees, line managers, managers, and Human Resource representatives and Occupational Health (OH) representatives. The $\mathrm{OH}$ representatives were professionals employed by the organisations and included physiotherapists and nurses. Where possible a trade union representative was also included; in this study this was the shop steward appointed by the trade union. A questionnaire survey was also disseminated at this time to a wider population. Table 3 details the interviewee sample.

Observed interactions were recorded in the form of field notes. The observations were collated through all stages of the research process including: liaison with organisations, structured interviews, discussion with steering groups, when in attendance at the organisation to conduct the qualitative interviews, interactions via telephone and email and when specific, relevant observable actions took place.

We devised a questionnaire to examine a variety of factors including employee health, organisational culture/climate, well-being and satisfaction 
and prevailing workforce arrangements. The focus was on the quality of work life, rather than the more traditional interest in the physical and psycho-social work environment. These are broader measures of health and wellbeing and included the workload level and the pressure to meet targets, the levels of influence over their work, sense of job satisfaction and working relationships. It is the employee perceptions of these potential wellbeing outcomes that is examined rather than the physical environment in which they operate. Although there is clearly a social element examined it is not our claim that this is a psycho-social evaluation. More specifically the questionnaire asked respondents to consider their organisational work environment. Questions examined the respondents' perception of organisational support for their wellbeing, for example promotion of a healthy lifestyle, and support on return to work, for example counselling and re-training. It also explored how the organisation encouraged employees to stay in work, for example with the use of flexi-time. This was to provide data at baseline (Phase 1) and 12 months later (Phase 2) on employees' satisfaction with current arrangements, and how this affected their perception of well-being and contributed to health-related issues. It was our aim to explore the perceptions of the experience: do people consider the workplace to be supportive to their health and wellbeing and does this change once innovation(s) have been introduced? It was not our intent to evaluate organisational compliance with health and safety assessments and regulation per se.

We examined several validated survey instruments including: the Workplace Employment Relations Survey questionnaire (Kersley et al., 2006) which covers working hours, job influence, job satisfaction, working arrangements, and training and skills; the Organisational Climate Measure (Patterson et al., 2005); and the Work Environment Scale (Moos, 1986), whose SF-36 yields an 8-scale health profile as well as summary measures of health-related quality of life. None covered all factors we wished to examine, and hence they were amalgamated and modified until we arrived at a manageable measure that covered the study's needs. To ensure comparability it was necessary questions had relevance in all organisations and were not specific to any particular organisational context.

Survey response rates are detailed in Table 3. We relied on the organisations to distribute the questionnaires, so that we do not have detailed data on patterns or reasons for non-response. Our information on the nature of the work forces suggests, however, that the samples were broadly representative. In the case of the organisation to which we devote most attention, we were able to compare patterns between the two rounds of surveys; there were no relevant differences between the two samples.

Frequencies, percentages and standard deviations were drawn together into a series of tables. Comparative analysis of pre- and post-intervention questionnaires was only conducted where response rates were over $20 \%$, and Phi-Cramer's V and Pearson tests were used to ascertain statistical significance at a confidence level of $95 \%$. As can be seen, response rates at the call centre in the two phases were acceptable. We should stress that the two surveys were distributed separately and that we do not have a panel design. We checked, however, the age and length of service distributions; these were identical in the two phases. 


\section{Tests of Effects}

There are several 'hard' tests of impact on direct and indirect outcomes. First, have workers' reports of organisations' attention to health changed over time? We look at two specific questionnaire items on health: whether workers reported that their organisations helped them to stay healthy, and whether they reported the presence of a range of facilities. We provided a list of items under each. Example items for things the respondents reported that the organisation had done were: 'modified work, e.g. light duties', and 'promoting healthy eating and lifestyle'. The organisational motivations for supporting such activities were not explored via the questionnaire; rather they were identified during the in-depth interviews and are reported in our earlier paper (Greasley et al, 2012).

Of the list of eight items, we address here only those six directly related to the individual, as opposed to two items that were more about policy. Respondents were also asked about seven 'facilities and services', such as counselling and stress management training. The focus of the questions contained in the survey is on workplace health promotion. What efforts were made on the part of the organisation in order to support its employees' health and wellbeing?

We also look at wider views of work. Some of these are reasonably proximate to health interventions, these included the management of work pressure is felt by employees to be taken seriously by managers and broad measures of the work environment, for example, caring for employees welfare was felt to have improved. There are of course many ways to measure the work environment but here we refer to employment relationships, workload demands and organisational support for health and wellbeing as perceived by employees.

Others are more distant, but might reasonably be expected to have changed if health interventions have any effects other than very specific ones. For example, is there a sense of loyalty to the organisation? Other areas are even more distant, for example the degree of job autonomy. We would not necessarily expect effects here.

Second, is there any evidence that changes in the call centre were more positive than those in the other two cases? We would expect that they would be, albeit with fewer differences the further we move away from the specific area of health interventions.

Third, do attitudes to health affect other attitudes? That is, if the interventions have effects, workers who report the presence of arrangements to provide workplace health promotion should also be the most likely to report positive views on the wider sets of attitudes listed above. If this is not the case, the interventions remain disconnected. A particular test here is whether any of the relevant associations strengthened over time. If the call centre was leading its workers to think differently, we might expect that reporting the presence of health arrangements will be more 
strongly linked to other attitudes at the time of the second survey.

\section{The Call Centre Story}

\section{Context and use of the intervention}

The environment of the call centre can be highly stressful, with employees dealing with many calls from potentially distraught customers. The organisation has undergone a considerable amount of change over recent years, having been sold by one large parent to another. Despite subsequent downsizing, the call centre itself was not affected directly by job losses; however the staff utilisation targets were increased from $75 \%$ to $95 \%$.

The initial levels of engagement with the study by managers were high, and the interventions were active and rigorous despite the lack of a history of well-being initiatives. For example, a strong promotional campaign of the value of the initiatives took place, and support from senior management was evidenced through the prioritisation of intervention training. Compared to other organisations, employees were much more involved in the process to encourage more support of the various initiatives in an attempt to alleviate the view that they are a management imposition. For example employees were involved in determining the type of intervention required and were part of the steering group established to aid the implementation of the intervention. The extensive changes here, in the context of a history without such change, would lead one to expect that there would not be scepticism about management or initiative fatigue; previous studies suggest that such conditions are associated with success (Marchington et al., 1994; Rosenthal et al., 1997).

Like the other organisations, the call centre underwent a number of significant changes including a takeover. Other management initiatives, to train line managers, were instigated in the form of 'coaching for success'. Changes in HR processes and procedures were also introduced including closer HR liaison in the Return to Work (RTW) process and a new recruitment procedure that eliminated the usage of agency staff and increased the employment of permanent staff. In order to maximize efficiency and meet customer demands, employees faced continual revisions to their shift patterns. The latter created a high level of tension and uncertainty and was a key source of complaint.

Along with these structural and procedural changes many initiatives which aimed to improve health and well-being were introduced. 'Fruity Fridays', as the name suggests, was one of the most visible changes; the focus on health also included information on BMI scales and links to local walks. The visible working environment also was developed with new breakout/rest areas with sofas, TV, and improved décor. However 
due to new budgetary constraints some changes were curtailed and future plans to improve the workplace for employees, for example the provision of a games room were shelved. Hence the changes were not in response to a legal duty of health and safety compliance; rather they aimed to promote the health and wellbeing of employees.

\section{Survey responses}

Table 4 shows survey responses to the two specific questions on health arrangements, notably the perception of organisational support for health promotion. There was a marked increase in the proportion of respondents reporting support to stay healthy. We also looked at the individual items. There were no clear differences between organisations on any of the six items at Phase 1. By Phase 2, the call centre showed strong increases, and clear differences from the other two organisations, on two items: provision of a supportive environment, and promoting healthy eating and lifestyle. On the latter, the proportion of positive replies rose from 15 to 77 per cent, while in the other two organisations the percentage remained below 10 . This is perhaps one of the more predictable outcomes of the study given the focus on healthy eating and lifestyle described above.

It was specific action, rather than formal facilities, that seems to have been important. Of the seven types of facilities identified, the call centre was rated at below the other organisations in the provision of six at Phase 1. It was ahead on 're-training' and this lead was retained at Phase 2. In other areas, it remained in general at lower levels.

Evidence of further effects becomes more limited as we move away from the immediate impact on views of health arrangements. There was no evidence that management was felt to give more attention to issues of work pressure, and if anything trends in the other two organisations were more favourable than they were in the call centre. This result is quite significant when we consider that the call centre had introduced a 'managing pressure positively' intervention. This intervention aimed specifically to tackle workplace pressure and reduce stress however the respondents did not feel that the organisation had given more attention to this area. There was some evidence that workers felt that the working environment had improved, with a clear shift between the two waves of surveys. The latter finding reflects concerted efforts on the part of managers at the call centre to enhance the aesthetics of the working environment.

The even more distant areas such as overall attitudes to the organisation and work satisfaction showed no clear trends. The notable rise in job security probably reflects the fact that agency staff were now being employed on permanent contracts. This change is notable, particularly in a call centre context for two reasons. Firstly it is a reversal of dominant organisational practice of employing temporary staff and secondly those in permanent positions are associated with better health outcomes (WHO, 2007). 
We then turned to the third form of test identified above: the nature of associations between reports of health interventions and other variables. We looked at the association in each survey and whether links had strengthened. Many of the variables are ordered in nature, and here the gamma statistic for cross-tabulations is used. We also created some additive measures, and performed t-tests for the difference of means between categories of response on the health questions.

Table 5 shows two illustrative sets of data. The first shows associations between workers' reports of health initiatives and whether managers were felt to have taken work pressures seriously. In Phase 1, 20 per cent of call centre workers felt that managers did take this issue seriously, as compared to 15 per cent overall; in Phase 2, these proportions rose to 25 and 20 per cent. The table shows the gamma statistics where each variable is categorized into three levels. In line with the impression from the raw figures, associations strengthened somewhat in all three organisations; but there was also a notable strengthening in the least engaged organisation, the police. There is thus little evidence that call centre workers saw a tighter link between attention to health and other issues. The second panel in Table 5 conducts a similar exercise in relation to perceived improvements in the work environment. Overall and in the call centre, there was a tendency for those reporting help with health issues to feel that the work environment had improved. There was no very marked difference from the other organisations, however, and the association's strength if anything weakened from Phase 1 to Phase 2.

We conducted similar analyses for other measures, namely, the extent of work pressure, influence, and satisfaction. There was no evidence of any strengthening of links in the call centre; if anything, they weakened. In the car manufacturer, there was an absence of any link at Phases 1 and 2. In the police force, links did strengthen.

\section{The Organisational Context}

So why did the call centre not outperform the other organisations, despite the high level of managerial commitment? There are a number of possibilities here; perhaps the most obvious is related to the fact that some improvements were to be found in all organisations so it would be difficult for the call centre to distinguish itself in this regard. A further argument could be made that a significant proportion of managers lacked some of the skills and knowledge required to support their staff and hence the interventions, while developing some skills, cannot be a replacement for these missing attributes. A further potential hindrance to improvements in reports of good management could be linked to the constant internal restructuring, which resulted for many workers in a change in their immediate line management. A final potential barrier for development of management relationships could be linked to the dissatisfaction with constantly changing shift times. The results of this were 
twofold. Firstly it increased employee uncertainty (although not necessarily job insecurity) and created difficulties in managing home and work. Secondly it meant that workers might not be working with their own line manager, hence limiting opportunities to develop relationships.

You just think what's this about, who is sat there and has decided, unless everybody just goes into a computer system somewhere and it spins the lottery number up. I really can't see, there's no method in it at all. There's no structure, it's just all over the place. No stability. (Employee)

However it should be noted that this problem was not peculiar to the call centre. Both the car manufacturer and the police force interviewees reported very similar concerns in regard to shift patterns. Indeed it is perhaps the most constant source of dissatisfaction for employees and so may have impacted all of our organisations.

One of the significant changes that may also have been expected but which did not occur is a significant reduction in workplace pressure. The goal of 'managing pressure positively' was a specific feature of the intervention. This issue is clearly highlighted during the interviews in relation to 'average handling times' (AHT). A new system had been introduced which in theory removed the focus on time that a call takes to answer; instead the focus is on customer service. Hence the pressure should have been removed from the call handlers, as they would now have the freedom to deal with calls as they saw fit. Indeed this is how several of the managers saw the changes to the system.

Now, you've got people who are hitting quality very, very well because they take a little bit longer over doing it, so they're being measured accurately for their performance, as they see it. They don't feel that pressure's there for AHT. (Manager)

However a disparity can be seen when we compare this perception with the views of employees who reported that processes were in place if 'targets' were not met. Hence they now felt increased pressure, as not only were they expected to achieve their hidden quantitative targets, they now also had to meet the quality of service objectives.

The first month we were given this relaxation of the AHT, then the relaxation was taken off us but our managers were still told that they had to achieve, their team's AHT had to be achieved so you go back into your one-to-one the next month and your manager says I know you're not scored on your AHT, but I want to set an action plan so we can bring it down. Where does that make sense? (Employee) 39

The story of a focus on productivity is reflected in the car manufacturer. Here, too, there are drives to improve performance e.g. through the use of 'leaner master classes'. It is arguable that one implication of this focus is to hinder the impact of the intervention, for no changes could be found in this organisation either. As D'Cruz and Noronha (2011) reported, employee wellbeing is indeed secondary to meeting apparent competitive demands. The relative improvements in the police force, despite low levels of management commitment to the health intervention, 
can be explained in terms of wider organisational changes, notably some stabilisation after a period of change and a reversion to shift systems that the workers preferred, after experiments with some new systems.

The take-over at the call centre also led to changes, notably a rise in the target level of staff utilisation from 75 to 95 per cent. This was clearly viewed as a factor increasing pressure on an already burdened workforce and one that was not seen as suitable for an industry where demand was erratic. Line managers also faced an increased emphasis on their own performance. This pressure, moreover, was often passed to the shop floor with employees feeling increased pressure as their manager strove to reach these new targets. It is plausible that the increase in work intensification may have detrimental consequences for employee health and wellbeing (WHO, 2007). Therefore the effects of attempts to improve direct and indirect health and wellbeing outcomes may be limited. Thompson (2003) describes the impact of take-overs in neo-liberal regimes as undermining efforts to maintain commitment and this is reflected here with managerial efforts compromised in order to meet the demands of the take-over organisation.

\section{Discussion and Conclusion}

We began with one piece of context and two main expectations. The context was provided by our prior study which showed, in line with previous research (Macfarlane et al., 2011), that the 'same' kind of intervention can be interpreted and implemented very differently in practice. From this basis, the first expectation was that managerial commitment would predict success. There was some limited evidence of this, in that the call centre saw improvements in workers' reports of attention to their health, and these were greater than in the other two organisations. Wider effects were, however, largely absent. Following DeJoy et al. (2010), we saw that the more distal potential effects were the weakest. Second, the organisational context was expected to be important. This proved to be the case, with various potential effects of the intervention being counteracted by other factors. Innovations occur in a context of constant organisational change which often results in greater demands being placed upon the employee. Like Nytrø (2000) we found that these factors cannot be ignored when implementing health and wellbeing innovations. We also considered the relationship between these two kinds of effect. Nielsen et al. (2010b) show, in a study comparing an intervention and a control group, that across both groups organisational changes were affecting employee well-being negatively. Some effects of improved managerial training were, however, still present. In our cases, even that of the call centre, there was less specific attention to such matters as training and the underpinnings of the intervention, and here the negative features of the context outweighted the intervention itself. In the language of Pawson et al. (2005), there were mechanisms that tended to produce effects, but these were weak in the two contexts where managerial commitment was low and far from strong in the call centre. Much other work reaches similar conclusions (e.g. Baldry et al., 2006; Thompson, 2003). 
It has to be recognised that, like many studies, this study took a limited period of one year in which to assess effects. It may take time for the effects of interventions to be felt. Storey et al. (1997: 227) underline the need to be 'be patient'. Yet there is also the risk that the positive effects of very specific changes will wear off. There was little evidence that the interventions studied here were being more deeply embedded in organisational practice, and given the other changes in the regulation of work we think it unlikely that more positive results would emerge in the longer term. In other words, over a longer period the specific positive effects in relation to healthy eating and the like might well decay, while there was no reason to think that further positive effects on more distal outcomes would emerge.

As indicated by Marchington et al. (1994), it is necessary to understand the organisational context. Despite the developments made in the call centre, the focus on targets and performance was a major constraint. Like D'Cruz and Noronha (2011) we found a focus on improving performance, as with the changing shift patterns, increasing staff utilisation and a change of measures in average handling time. An initiative such as 'managing pressure positively' cannot compete with broader organisational changes that demand more from employees. There is clear dissonance between the desire and effort to support employee wellbeing at an individual level on the one hand and wider organisational pressure on other. The evidence suggests that increases in work intensification are not conducive to employee wellbeing (WHO, 2007).Without recognition of the wider process and contextual issues the impact of health and wellbeing innovations may well be minimal (Nytrø et al, 2000).

Despite the apparent managerial commitment to these interventions, therefore, managers are constrained by the wider socio-economic contexts in which they operate. Thompson's (2003) notion of disconnected capitalism or why employers cannot keep their side of the bargain (at least to the extent they would like) is aptly demonstrated in this empirical case study. The managers' clearly demonstrated commitment to the health and well-being initiatives but the competitive market in which the organisation operated resulted in counter trends that negated the impact of these interventions. Attempting to make predictions on the basis of managerial commitment is therefore unreliable, certainly in terms of broader impacts.

We recognise that the organisation did not make significant changes to the workplace practices to reduce organisational causes of stress. The reluctance to undertake such action is however commonplace (Nytrø et al, 2000, Taylor et al, 2003) and so the call centre is not distinct in this regard. However it did provide a context that is relatively rare. The call centre was a self-selected case, the intervention offered potential benefits to both employees and the organisation, and there were high levels of enthusiasm and commitment. Despite this, the intervention still did not produce significant outcomes. The suggestion of reports to governments as to how organisations might successfully engage in HR initiatives (MacLeod and Clarke, 2009) were in evidence here. The support of senior management, together with practical advice and support, was clear, and yet outcomes were limited. This raises the question that, if an organisation which appears to be doing all the 'right things', at least according to Macleod and Clarke (2009) and in comparison to other self-selected organisations cannot achieve significant outcomes, how difficult it would 
be for organisations who find themselves in less favourable conditions.

The fact that organisational initiatives often 'fail' is well-established. That said, we feel that we have made several contributions. First, the area of health interventions is potentially one of more shared interests between worker and employer than would be true in many other aspects of HR, and all three of our organisations were highly self-selected in that they were initially eager participants in the interventions studied here. Yet results were limited. Where managerial commitment is in evidence it is not sufficient to overcome the context of competitive demands.

Secondly, and more analytically, we have traced where health interventions did or did not have an impact on employees and we have identified the constraints even in a highly committed organisation. The importance of linking interventions to mundane aspects of work organisation such as shift systems and performance targets sounds obvious, but it bears repetition: even in the favourable circumstances of our organisations, all of which were self-selected for their broad commitment to the idea of employee health, embedding specific interventions so that they had effects on employee wellbeing in a broad sense proved very hard. This approach can be located in emerging frameworks to analyse interventions. We have illustrated the value of the four-fold approach recommended by Nielsen and Abildgaard (2013). The first category embraces organisational actors, and here, and in our fuller account of the origins of the interventions (Greasley et al, 2012), we have discussed the reasons why actors choose interventions, including how and why cases of interventions are highly self-selected. Second comes their mental models; as discussed above, actors' interpretations of the aims and results of interventions depend on these maps rather than hard measures of 'results'. Thirdly, we have focused on context. Finally, we have assessed outcomes, including 'positive and negative effects' (Nielsen and Abildgaard, 2013: 290). That said, future research might give more systematic attention to at least two of these: the social processes through which interventions are defined and assessed, a theme which we pursued in only a limited depth; and the range of long-term outcomes of interventions, including intended and unintended effects and also ostensive and more latent objectives. By the last contrast, we mean that interventions often have stated goals but also unstated ones such as 'changing cultures'. It is important to address these latter kinds of objectives, both in terms of hidden aims that managers may have and employees’ perceptions. For example, if employees fear, rightly or wrongly, that an intervention has secret goals, their responses will be affected.

Thirdly, through an empirical, real-time assessment we have drawn attention to the value of summative and formative forms of evaluation. A frequent criticism of the evaluation literature generally and wellbeing initiatives specifically is the focus solely on quantitative outcomes (Nielsen et al, 2010a). Here we have demonstrated that in order to understand the outcomes of such initiatives in terms of the what question, one must also explore the how and why.

\section{Acknowledgements}


The authors would like to thank and acknowledge the involvement of Professor Jeremy Dale and Dr Denise Baker-McClearn in this study. They also thank the Work 2 Health consultancy who provided the interventions and reviewers for helpful comments. This work was supported by the BUPA Foundation.

\section{References}

Bach S (2005) Personnel management in transition. In: Bach S (ed.) Managing Human Resources, $4^{\text {th }}$ edn. Oxford: Blackwell.

Baldry C, Taylor P and Bain P (2006) 'Bear with me': the problems of health and well-being in call centre work. In: Wood G and James P (eds) Institutions, Production and Working Life. Oxford: Oxford University Press.

Bambra C, Egan M, Thomas S, Petticrew M, and Whitehead M (2009) The psychosocial and health effects of workplace reorganisation. A systematic review of task restructuring interventions. Journal of Epidemiology and Community Health 61(6):1028-37.

Baril R, Clare J, Friesen M, and Stock D (2003) Management of return-to-work programs for workers with musculoskeletal disorders: a qualitative study in three Canadian Provinces. Social Science and Medicine, 57(11): 2101-14.

Black C (2008) Working for a Healthier Tomorrow. Dame Carol Black's review of the health of Britain's working age population. Available at www.gov.uk/government/uploads/system/uploads/attachment_data/file/209782/hwwb-working-for-a-healthier-tomorrow.pdf

Bohle P and Quinlan M (2000) Managing Occupational Health and Safety: A Multi-disciplinary Perspective. Melbourne: Macmillan.

CIPD (2009) Annual Survey. Available at: www.cipd.co.uk

Cox T, Karanika, M, Griffiths, A and Houdmont J (2007). Evaluating organisational-level work stress interventions: beyond traditional methods. Work and Stress, 21(3): 348-62.

D’Cruz P and Noronha E (2011) High commitment management practices re-examined: the case of Indian call centres. Economic and Industrial Democracy 32(2): 185-205.

DeJoy DM, Wilson MG, Vandenberg RJ, McGrath-Higgins AL, and Griffin-Blake CS (2010) Assessing the impact of healthy work organisation intervention. Journal of Occupational and Organisational Psychology 83(1): 139- 65.

Dieleman M, Gerretsen B, and van der Wilt GM (2009) Human resource management interventions to improve health workers’ performance in 
low and middle income countries: a realist review. Health Research Policy and Systems 7(7): Open Access journal, no page numbers.

Edwards P K (2005) The puzzle of work: insecurity and stress and autonomy and commitment. In: Heath AF, Ermisch J and Gallie D (eds) Understanding Social Change. Oxford: Oxford University Press.

Greasley K, Edwards P K, Baker-McClearn D, and Dale J (2012) Why do organisations engage in HR initiatives? A test case of a health and wellbeing intervention. Employee Relations. 34, (4) 443-462.

Harrison B (1994) Lean and Mean: the Changing Landscape of Corporate Power in the Age of Flexibility. New York: Basic Books.

Hyman J (2006) The remaking of work: empowerment or degradation? In: Wood G and James P (eds) Institutions, Production and Working Life. Oxford: Oxford University Press.

Ichniowski C and Shaw K (2009) Insider econometrics: empirical studies of how management matters. NBER Working Paper No. 15618, Cambridge, MA, National Bureau of Economic Research.

Idler E and Benyamini Y (1997) Self-rated health and mortality: a review of 27 community studies. Journal of Health and Social Behavior 38(1): 21-37.

Kersley B, Alpin C, Forth J, Bryson A, Bewley H, and Dix G (2006) Inside the Workplace: Findings from the 2004 Workplace Employment Relations Survey. London: Routledge.

Legge K (2005) Human Resource Management: Rhetoric and Realities, $2^{\text {nd }}$ edn. Basingstoke: Palgrave.

Macfarlane F, Greehalgh T, Humphrey C, Hughes J, Butler C, and Pawson, R (2011) A new workforce in the making? A case study of strategic human resource management in a whole-system change effort in healthcare. Journal of Health Organisation and Management, 25(1): 55-72.

MacLeod D, and Clarke N (2009) Engaging for Success: Enhancing Performance through Employee Engagement. Available at http://www.mbsportal.bl.uk/secure/subjareas/hrmemplyrelat/bis/11152909-1075engaging09.pdf.

Marchington M, Wilkinson A, Ackers P, and Goodman J (1994) Understanding the meaning of participation: views from the workplace. Human Relations 47(8): 867-94.

Marmot M, Feeney A, Shipley M, North F, and Syme S (1995) Sickness absence as a measure of health status and functioning: findings from the Whitehall II study. Journal of Epidemiology and Community Health 49(1): 124-30.

Moos RH (1986) Work Environment Scale Manual, $2^{\text {nd }}$ edn. Palo Alto: Consulting Psychologists Press.

Murphy LR (1988) Workplace interventions for stress reduction. In: Cooper CL and Payne R (eds) Causes, Coping and Consequences of Stress at Work. New York: Wiley. 
Nielsen K and Abildgaard JS (2013) Organizational interventions: a research-based framework for the evaluation of both process and effects. Work and Stress 27(3): 278-97.

Nielsen K, Taris TW and Cox T (2010a) The future of organisational interventions: addressing the challenges of today's organisations. Work and Stress, 24(3): 219-33.

Nielsen K, Randall R and Christensen KB (2010b). Does training managers enhance the effects of implementing team-working? A longitudinal mixed methods field study. Human Relations, 63(11): 1719-41.

Nytrø, K, Saksvik PØ, Mikkelsen A, Bohle P and Quinlan M (2000) An appraisal of key factors in the implementation of occupational stress interventions. Work and Stress 14(3): 213-225.

Patterson MG, West MA, Shackleton VJ, Dawson JF, Lawthom R, Maitlis S, Robinson DL and Wallace AM (2005) Validating the organisational climate measure: links to managerial practices, productivity and innovation. Journal of Organisational Behavior 26(2): 379-408.

Pawson R, Greenhalgh T, Harvey G and Walshe K (2005) Realist review: a new method of systematic review designed for complex policy interventions. Journal of Health Services Research and Policy, 10(suppl 1): 21-34.

Pransky G, Gatchel, R, Linton SJ, and Loisel P (2005) Improving return to work research. Journal of Occupational Rehabilitation 15(4): 525-42.

Rainbird H, Sutherland J, Edwards P, Holly L and Munro A (2003). Employee voice and training at work: an analysis of case studies and WERS 1998. Employment Relations Research Series 21, Department of Trade and Industry. London: DTI.

Randall R, Cox T and Griffiths A (2007) Participants’ accounts of a stress management intervention. Human Relations, 60(8): 1181-1209.

Rosenthal P, Hill S, and Peccei R (1997) Checking out service: evaluating excellence, HRM and TQM in retailing. Work, Employment and Society 11(3): 481-503.

Shaw WS, Robertson MM, Pransky G, and McLellan RK (2003) Employee perspectives on the role of supervisors to prevent workplace disability after injuries. Journal of Occupational Rehabilitation 13(3): 129-42.

Sisson K, and Storey J (2000) The Realities of Human Resource Management. Buckingham: Open UP.

Smulders P, and Nijhuis F (1999) The job demands- job control model and absence behaviour: results of a 3-year longitudinal study. Work and Stress, 13(1): 115-31. 
Storey, J, Sisson K and Edwards P (1997) Managers in the Making. London: Sage.

Taylor P, Baldry C, Bain B, and Ellis V (2003) 'A unique working environment': health, sickness and absence management in UK call centres. Work, Employment and Society 17(3): 435-58.

Thompson P (2003) Disconnected capitalism: or why employers can't keep their side of the bargain. Work, Employment and Society, 17(3): 35978.

Tombs S and Whyte D (2012) Reshaping health and safety enforcement. In: L. Dickens (ed.) Making Employment Rights Effective. Oxford: Hart. Vallas S (2003) Why teamwork fails: obstacles to workplace change in four manufacturing plants. American Sociological Review, 68(1): 223-50.

Wilkinson A, Marchington M, Goodman J, and Ackers P (1992) Total quality management and employee involvement. Human Resource Management Journal 2(4), 1-20.

World Health Organisation (2007) Employment Conditions and Health Inequalities. Available at: http://www.who.int/social_determinants/resources/articles/emconet_who_report.pdf

Wright M and Edwards P (1998) Does teamworking work and, if so, why? A case study in the aluminium industry'. Economic and Industrial Democracy, 19(1): 59- 90. 
Table 1: Case Study Descriptions

\begin{tabular}{|l|l|l|l|}
\hline $\begin{array}{l}\text { Case Study } \\
\text { Organisation }\end{array}$ & Recovery Service & Car Manufacturer & Police Force \\
\hline Economic Sector & $\begin{array}{l}\text { Breakdown and } \\
\text { Insurance }\end{array}$ & $\begin{array}{l}\text { Manufacturing } \\
\text { Automobiles }\end{array}$ & Police Force \\
\hline Type of Workforce & Call centre operatives & $\begin{array}{l}\text { Semi-skilled shop- } \\
\text { floor operatives }\end{array}$ & $\begin{array}{l}\text { Police officers and } \\
\text { civilian staff }\end{array}$ \\
\hline Organisational Size & $5000+$ & $5000+$ & Less than 5000 \\
\hline Public / Private & Private & Private & Public \\
\hline $\begin{array}{l}\text { Existence of explicit } \\
\text { health and absence } \\
\text { management Policies }\end{array}$ & $\begin{array}{l}\text { Yes in the form of } \\
\text { guidelines }\end{array}$ & $\begin{array}{l}\text { Explicit absence } \\
\text { policies but health } \\
\text { policies vague }\end{array}$ & $\begin{array}{l}\text { Explicit Absence } \\
\text { Policy }\end{array}$ \\
\hline Department studied & Call Centre & $\begin{array}{l}\text { One manufacturing } \\
\text { department }\end{array}$ & $\begin{array}{l}\text { Road Traffic Police } \\
\text { and Call Centre } \\
\text { Staff }\end{array}$ \\
\hline
\end{tabular}


Table 2.Process of Interventions in Case study organisations

\begin{tabular}{|c|c|c|c|}
\hline & Recovery Service & Car Manufacturer & \begin{tabular}{|l|} 
Police Force \\
\end{tabular} \\
\hline $\begin{array}{l}\text { Status of } \\
\text { Intervention }\end{array}$ & $\begin{array}{l}\text { Intervention training completed } \\
\text { Intervention roll-out across department commenced } \\
\text { Further roll-out planned for the future }\end{array}$ & $\begin{array}{l}\text { Intervention training completed } \\
\text { Future roll-out planned }\end{array}$ & $\begin{array}{l}\text { No training and/or action taken in } \\
\text { response to the development documents }\end{array}$ \\
\hline $\begin{array}{l}\text { Organisational } \\
\text { Change }\end{array}$ & $\begin{array}{l}\text { Development of Return to Work process } \\
\text { Recruitment from permanent headcount } \\
\text { Healthy eating and activity innovations e.g. 'Fruity } \\
\text { Fridays' } \\
\text { Management training initiative 'coaching for success' } \\
\text { Improvement to recreational areas } \\
\text { Organisational take-over } \\
\text { Work targets amended to include more qualitative } \\
\text { measures }\end{array}$ & $\begin{array}{l}\text { Streamlining attendance process } \\
\text { Fast track of Occupational health } \\
\text { provision for certain conditions } \\
\text { Introduction of counselling service } \\
\text { Changes to shift pattern. Removal of } \\
\text { night shifts in response to changes in } \\
\text { economic climate } \\
\text { 'Leaner' master classes introduced }\end{array}$ & $\begin{array}{l}\text { Shift pattern amended } \\
\text { New senior management } \\
\text { Duties of police officers enlarged } \\
\text { Civilianising posts traditionally filled by } \\
\text { police officers who are in the } \\
\text { rehabilitation process }\end{array}$ \\
\hline $\begin{array}{l}\text { Absence } \\
\text { Levels }\end{array}$ & $\begin{array}{l}\text { Pre-intervention: } 4.9 \% \\
\text { Post-intervention: } 4.6 \%\end{array}$ & $\begin{array}{l}\text { Pre-intervention: } 7 \% \\
\text { Post-intervention: } 5 \%\end{array}$ & $\begin{array}{l}\text { Pre-intervention: } 9.9 \% \text { (Police staff), } \\
2.7 \% \text { (Police officers) } \\
\text { Post-intervention: } 8.4 \% \text { (Police staff), } \\
5.0 \% \text { (Police officers) }\end{array}$ \\
\hline
\end{tabular}


Table 3: Interviewee Sample and Questionnaire Response Rates

\begin{tabular}{|c|c|c|c|}
\hline $\begin{array}{l}\text { Case Study } \\
\text { Organisation }\end{array}$ & $\begin{array}{l}\text { Number of } \\
\text { interviewees } \\
\text { (from semi- } \\
\text { structured } \\
\text { interviews) }\end{array}$ & Interviewee details & Questionnaire Details \\
\hline $\begin{array}{l}\text { Recovery } \\
\text { Service Call } \\
\text { Centre }\end{array}$ & $\begin{array}{l}\text { Phase 1: } 11 \\
\text { Phase 2: } 10\end{array}$ & $\begin{array}{l}4 \text { Employees } \\
1 \text { TU Employee } \\
3 \text { Supervisors } \\
1 \text { Manager } \\
1 \text { OH } \\
1 \mathrm{HR}\end{array}$ & $\begin{array}{l}\text { Phase } 1: 225 \text { distributed, } \\
191 \text { returned }(85 \%) \text {. Phase } \\
2: 339 \text { distributed, } 79 \\
\text { returned }(21 \%) \text {. }\end{array}$ \\
\hline $\begin{array}{l}\text { Car } \\
\text { manufacturer }\end{array}$ & $\begin{array}{l}\text { Phase 1: } 13 \\
\text { Phase 2: } 12\end{array}$ & $\begin{array}{l}4 \text { Employees } \\
1 \text { TU Employee } \\
3 \text { Supervisors } \\
1 \text { Manager } \\
1 \text { Senior Manager } \\
2 \text { OH } \\
1 \text { HR }\end{array}$ & $\begin{array}{l}\text { Phase 1: } 139 \text { distributed, } \\
113 \text { returned }(81 \%) \text {. Phase } \\
\text { 2: } 125 \text { distributed and } 92 \\
\text { returned }(74 \%) \text {. }\end{array}$ \\
\hline Police Force & $\begin{array}{l}\text { Phase 1: } 12 \\
\text { Phase 2: } 9\end{array}$ & $\begin{array}{l}4 \text { Employees } \\
2 \text { Supervisors } \\
2 \text { Managers } \\
2 \text { Senior Managers } \\
1 \text { OH } \\
1 \text { HR }\end{array}$ & $\begin{array}{l}\text { Phase 1: } 640 \text { distributed, } \\
285 \text { returned }(45 \%) \text {. Phase } \\
\text { 2: } 567 \text { distributed, } 212 \\
\text { returned (37\%) }\end{array}$ \\
\hline
\end{tabular}


Table 4. Changes in Attitudes over Time (\%)

\begin{tabular}{|c|c|c|}
\hline & Phase 1 & Phase 2 \\
\hline & \multicolumn{2}{|c|}{ Organisation provides support to stay healthy } \\
\hline Call Centre & 44 & 82 \\
\hline Car Manufacturer & 32 & 40 \\
\hline \multirow{2}{*}{ Police Force } & 51 & 50 \\
\hline & \multicolumn{2}{|c|}{ Organisation provides facilities } \\
\hline Call Centre & 82 & 90 \\
\hline Car Manufacturer & 88 & 90 \\
\hline \multirow[t]{2}{*}{ Police Force } & 94 & 97 \\
\hline & \multicolumn{2}{|c|}{ Management of work pressure is taken seriously } \\
\hline Recovery Service & 19 & 24 \\
\hline Car Manufacturer & 6 & 19 \\
\hline \multirow[t]{2}{*}{ Police Force } & 16 & 53 \\
\hline & \multicolumn{2}{|c|}{ Working environment has improved } \\
\hline Call Centre & 28 & 54 \\
\hline Car Manufacturer & 43 & 30 \\
\hline \multirow[t]{2}{*}{ Police Force } & 35 & 32 \\
\hline & \multicolumn{2}{|c|}{ Managers keep employees informed } \\
\hline Cell Centre & 62 & 75 \\
\hline Car Manufacturer & 40 & 58 \\
\hline \multirow[t]{2}{*}{ Police Force } & 53 & 69 \\
\hline & \multicolumn{2}{|c|}{ Positive attitudes to organisation } \\
\hline Call Centre & 60 & 65 \\
\hline Car Manufacturer & 42 & 42 \\
\hline \multirow[t]{2}{*}{ Police Force } & 85 & 87 \\
\hline & \multicolumn{2}{|c|}{ Good relations between managers and employees } \\
\hline Call Centre & 50 & 71 \\
\hline Car Manufacturer & 13 & 25 \\
\hline \multirow[t]{2}{*}{ Police Force } & 45 & 66 \\
\hline & \multicolumn{2}{|c|}{ Satisfaction with job security } \\
\hline Call Centre & 33 & 55 \\
\hline Car Manufacturer & 16 & 19 \\
\hline \multirow[t]{2}{*}{ Police Force } & 70 & 86 \\
\hline & \multicolumn{2}{|c|}{ Increased level of satisfaction at work } \\
\hline Call Centre & 22 & \\
\hline Car Manufacturer & 4 & \\
\hline \multirow[t]{2}{*}{ Police Force } & & 21 \\
\hline & \multicolumn{2}{|c|}{ Influence over work } \\
\hline Call Centre & 79 & 90 \\
\hline Car Manufacturer & 77 & 67 \\
\hline \multirow[t]{2}{*}{ Police Force } & 99 & 99 \\
\hline & \multicolumn{2}{|c|}{ Satisfaction with job at P1 } \\
\hline
\end{tabular}




\begin{tabular}{lll}
\hline Call Centre & 87 & 81 \\
\hline Car Manufacturer & 62 & 49 \\
\hline Police Force & 94 & 97 \\
\hline
\end{tabular}

Table 5. Cross-tabulation (gamma) statistics

'Organisation takes management of work pressure seriously' cross-tabulated with 'measures to help employee health'.

\begin{tabular}{|c|c|c|}
\hline & Phase 1 & Phase 2 \\
\hline Call Centre & $-.25 * *$ & $-.38 * *$ \\
\hline Car Manufacturer & +.15 & -.21 \\
\hline Police Force & $-.28^{* * *}$ & $-.41^{* * *}$ \\
\hline All & $-.22 * * *$ & $-.36 * * *$ \\
\hline \multicolumn{3}{|c|}{ 'Work environment has improved' cross-tabulated with 'measures to help employees' health' } \\
\hline & Phase 1 & Phase 2 \\
\hline Call Centre & $0.53 * * *$ & 0.34 \\
\hline Car Manufacturer & -0.00 & $0.49 *$ \\
\hline Police Force & 0.23 & 0.14 \\
\hline All & $0.27 * *$ & $0.32 * * *$ \\
\hline
\end{tabular}

Note: $* * *=$ sig at $<1 \% ; * *=1-5 \% ; *=5-10 \%$. 